Free Hospital, London, in July 1966. 50 people from 12 countries participated, including acknowledged international authorities. The standard of papers is high and the production in book form by Blackwell is, of course, excellent.

The material is presented in five sections. (1) Origin of bile pigments (6 papers). (2) Structure of bile pigments (10 papers). (3) Hepatic transport of bile pigments ( 7 papers). (4) Bilirubin metabolism in obstructive jaundice (3 papers). (5) Renal excretion of bile pigments (7 papers). (6) A final section deals with the histochemical demonstration of bilirubin and its conjugates in tissue.

Topics discussed include 'early bilirubin'; haemolysis and bilirubin production; the chemistry of bile pigments; protein binding; hepatic uptake and transport; and excretion in bile and urine. The kinetics of bilirubin distribution in the body and alternate pathways of excretion in complete biliary obstruction are considered. The excretion of urobilinogen is dealt with in one paper.

The standard of papers varies, and inevitably there is much repetition of data. References to published works are given at the end of each paper. Even though they are seldom complete, repetition often occurs. A single section giving detailed references, including titles, would have been better.

It is not clear to whom this book is directed. Certainly it will be of great interest to the participants, but other workers in this specialist field will probably prefer to read in full the original articles from which these papers are drawn. From the clinician's point of view, though there is much of interest, this is not easily accessible in the mass of information, much of which concerns animal experimentation.

In short, a better edited and integrated account would have been of value to clinicians, whereas the data presented are not in sufficient detail for the research worker already engaged in this field.

Reticuloendothelioses in Childhood: A Clinical Survey. By Harold W. K. Dargeon. (Pp. xii + 127; 40 figures +9 tables. \$8.50.) Springfield, Illinois: Charles C. Thomas. 1966.

This slim volume is indeed expensive, and not particularly informative. It is concerned mainly with the well-known reticuloendothelial disorders such as eosinophilic granuloma of bone, Hand-Schuller-Christian disease, and Letterer-Siwe disease, but also includes a short section on xanthoma, Gaucher's disease, and Nieman-Pick disease. There is a brief introduction on the general aspects of these disorders and their classification. This section is naive and does not elucidate the various concepts concerning the function of the reticuloendothelial system in immune disorders.

The various forms of reticuloendothelial disease are then described briefly, though if Nieman-Pick and Gaucher's disease are to be included there is little to justify omission of other lipidoses. A clinical review of 64 cases of true reticuloendotheliosis is followed by a short section on treatment, and the monograph concludes with a recapitulation of the author's views. There is a short bibliography arranged under subject headings. The author admits to having pruned the references to a minimum, but it is a pity that very few up-to-date ones have been included. Most of the classical papers are mentioned. The book is well produced and the illustrations are clear and to the point.

The subject is a difficult one and many diagnostic problems exist among the various disorders included in this book. It appears unlikely, however, that the clinician would gain much insight from reading this work, and it will be of little interest to the research worker. It is said to have been produced with the clinician and student in mind, but both would receive just as adequate information from one of the better standard paediatric textbooks.

Pediatric and Adolescent Gynecology. By HowARD W. Jones, JR., and Richard H. Heller. (Pp. ix + 333; 215 figures. 92s.) Edinburgh: E. \& S. Livingstone. 1966.

This is a well-written, infomative, and beautifully illustrated textbook of some 333 pages covering an immensely important part of medicine. It is divided into six sections-embryology, anatomy and physiology, anomalies, infections, and rare tumours, and endocrine disorders, and has an extensive bibliography as well. The first two sections are short but contain the important foundations for the sections to follow. All the commoner developmental abnormalities are dealt with especially with regard to surgical treatment. The part dealing with endocrine disorders is very largely concerned with the commoner disorders of sexual development and describes clearly their particular chromosomal patterns, endocrine findings, and clinical features. If any one section merits especial acclaim it is this, not only for the completeness of its coverage but also because it makes a difficult subject understandable.

This book can be thoroughly recommended to the undergraduate to provide him with important information, and also to the postgraduate as a reference in the management of problems, some of which may be met only rarely.

Endocrinology of the Testis. Edited by G. E. W. Wolstenholme and Maeve O'Connor. (Ciba Foundation Colloquia on Endocrinology, Vol. 16.) (Pp. xiii +331 ; illustrated. 60s.) London: J. \& A. Churchill. 1967.

This volume is the last in the series of Colloquia on Endocrinology by the Ciba Foundation. Like the previous ones, it represents a series of papers presented at a meeting with an invited audience of experts. Each paper is followed by discussion and a general discussion concludes the book. This book is essentially for the expert, and contains up-to-date information in many specialized spheres of normal and abnormal testicular embryology, histology, steroid biosynthesis, etc. The clinical endocrinologist may feel disappointed that so little space is devoted to the problems of diagnosis and 
treatment of the various types of testicular deficiency in man. On the other hand, there is a feast of information for the reader who wishes to keep abreast of the more scientific aspects of testicular function. The differentiation of the human embryonic testis is described and related to the ultimate phenotype. The time relationships of enzyme development in the testis have important bearings on the concept that, to be effective, enzymes and hormones must reach their maximum concentration at the right time in development. This point appears again later in the book when resistance to androgens in hypogonadal adults is discussed.
There is a series of papers dealing with the synthesis and secretion of androgens and oestrogens from normal and abnormal testes and the indications suggest the point at which ICSH (or LH) acts in the biosynthetic chain. The paper from Samuel's department may have an even wider significance because it may give a clue to the difficult problem of adrenal androgen synthesis.

This book, with contributions by many of the world's experts, will be essential to all those endocrinologists interested in the scientific side of their subject and contains much of value for reference purposes for the clinical endocrinologist.

\section{European Society for Paediatric Nephrology Foundation Meeting}

The foundation meeting of this Society took place in Glasgow from September 17-21, 1967 and was attended by some 70 persons. The Society, to date, consists of 43 members from 20 European countries. The founders are Dr. Gavin C. Arneil, Department of Child Health, University of Glasgow, and Dr. Harman A. W. M. Tiddens, Wilhelmina Children's Hospital, Utrecht, Netherlands.

During the course of the three-day meeting, 30 scientific papers were read, and the foundation lecture was given by Professor Henry L. Barnett, of the Albert Einstein College of Medicine, New York, U.S.A.

The meetings took place in the Department of Child Health, University of Glasgow, at the Royal Hospital for Sick Children, Yorkhill, Glasgow. Receptions

\section{Editorial Notice}

It has been decided to introduce reviews of films on subjects of paediatric interest. Dr. Hugh Jolly has joined the Committee as film reviewer, and will be glad to have notice of any such films known to our readers, together with information on their nature and how they can be obtained on loan for viewing. This should be addressed to Dr. Hugh Jolly, Children's Department, Fulham Hospital, Hammersmith, London W.6. to the new Society were given by the University of Glasgow and by the Royal College of Physicians and Surgeons of Glasgow. The foundation dinner of the Society was held under the auspices of the University of Glasgow and the meeting has led to the formation of a new scientific body.

Arrangements are in hand for the next meeting in Utrecht in 1968.

Officers of the Society are as follows.

Secretary: Dr. Gavin C. Arneil, Department of Child Health, University of Glasgow, Royal Hospital for Sick Children, Yorkhill, Glasgow C.3.

Assistant Secretary: Dr. Harman A. W. M. Tiddens, Wilhelmina Children's Hospital, 137 Nieuwe Gracht, Utrecht, Netherlands.

Sirs,

\section{Correspondence}

Concerning our article 'Congenital Hepatic Fibrosis in Jamaican Children' (vol. 43, 379), Case 5 has recently been readmitted with increasing splenomegaly and evidence of hypersplenism. Marrow examination (Dr. P. Milner) suggests that she has a lipid storage disease of the Niemann-Pick type. In the absence of a further liver biopsy, we feel some doubt must, therefore, be thrown on the diagnosis of congenital hepatic fibrosis, and the fibrosis seen in her case (and possibly her sister, Case 4) may be due to a lipid storage disease, though we had previously found no evidence of this.

Marigold J. Thorburn 